\title{
Psychological distress among adults admitted to medical and surgical wards of a Regional Referral Hospital, Uganda
}

\author{
*Rukundo ZG ${ }^{1}$, Nakasujja N², Musisi $\mathrm{S}^{2}$ \\ 1. Department of Psychiatry, Mbarara University of Science and Technology'Mbarara, Uganda \\ 2. Department of Psychiatry, Makerere University College of Health Sciences, Kampala, Uganda
}

\begin{abstract}
Background: Physical illness is commonly associated with psychological distress that may be a direct effect of the illness or an adjustment in coping with the physical illness or its treatment. Little is known about psychological distress of patients on general wards in developing countries.

Objectives: This study aimed to determine the extent and associations of psychological distress among adult in-patients on medical and surgical wards of Mbarara hospital in Uganda.

Methods: It was a cross sectional descriptive study among 258 adult in-patients. The WHO endorsed self report questionnaire (SRQ-25) was used to assess psychological distress with a cut off of 5/6. The MINI International Neuropsychiatric Interview (MINI) was used to identify specific psychiatric disorders. Cross-tabulations and multivariate analysis was used to analyze the relationship between psychological distress and different factors.

Results: One hundred and fifty eight individuals (61\%) had psychological distress. One hundred and nine (42\%) met criteria for at least one major psychiatric diagnosis. Only $6 \%$ of these were recognized by the attending health workers. Psychological distress was significantly associated with previous hospitalizations, ward of admission and marital status.

Conclusions: There is a high level of psychological distress among the physically ill and it is often unrecognized and untreated.
\end{abstract}

Key words: psychological distress, physical illness, psychiatric

African Health Sciences 2013; 13(1): 82 - 86 http://dx.doi.org/10.4314/ahs.v13i1.12

\section{Introduction}

Psychological problems associated with physical illness in general hospitals are often undetected. Much time and resources are spent on unwarranted investigations and treatments. These results into worsening of the prognosis of medical conditions hence increased morbidity and mortality. ${ }^{1,2,3,4}$ This could due to the direct effect of psychological distress on the physical illness or non-adherence to treatment or a combination of factors. ${ }^{5,6}$ The psychological distress among the physically ill could be due to difficulties in coping with physical disability or a direct result of the physical illness especially if it threatens independence and livelihood. ${ }^{7,8}$ In addition, treatment (e.g. medications) given for the physical illnesses may exacerbate pre-existing psychological

*Corresponding author:
Dr. Godfrey Zari Rukundo
Mbarara University of Science and Technology
Child \& Adolescent Psychiatrist
Mbarara Regional Referral Hospital
P. O. Box 1410
Mbarara- Uganda
Tel: +256772663671
Email:rukundogzari@yahoo.co.uk
grukundo@must.ac.ug

problems or precipitate them for the first time. ${ }^{9,10,}$ 11,12

The study by Nakasuija in 2002 in Uganda, ${ }^{13}$ reported a $48 \%$ prevalence of psychiatric disorders among the elderly in-patients on the non-psychiatric wards of the national referral general hospital (Mulago). Surprisingly, only $6 \%$ of them had been identified by the attending doctors. In the same hospital, Katorogo ${ }^{14}$ reported depression in 35\% of the in-patients on the general medical wards with only $20 \%$ recognized by the attending doctors and therefore, left untreated. To our knowledge, no studies have been conducted amongst the medically ill in regional referral hospitals in Uganda, yet there is need for such knowledge in the implementation of the recommended integration of mental health service into the general health services. Therefore, this study aimed to assess the extent and associations of psychological distress on medical and surgical wards of Mbarara hospital as a prototype of regional referral hospitals in Uganda.

\section{Methods}

This was a descriptive cross sectional study of 258 patients on two medical and two surgical wards of 
Mbarara Regional Referral Hospital in Western Uganda in 2004. Mbarara hospital is the biggest in the region and is also the teaching hospital for Mbarara University of Science and Technology Medical School. It has a capacity of 350 beds but admits over 15,000 patients in a year. At the time of the study, an average of about 335 patients was being admitted on the general medical and surgical wards per month. Participants were adults who gave informed consent to participate in the study and were consecutively recruited with in the first three days of admission.

The study employed a socio-demographic questionnaire, the Self report questionnaire (SRQ25) and the Mini International Neuropsychiatric Interview (MINI). All the questionnaires were translated into the local language (RunyankoreRukiga) spoken by majority of the people in the catchment area. The MINI was administered to participants who scored 6 or more on the SRQ-25 to identify specific psychiatric disorders that required specific treatment. The questionnaires were interviewer administered to ensure uniformity as some of the respondents could not read and write. The data obtained were analyzed using SPSS 18.0 for windows. Psychological distress as measured by SRQ 25 score of $>6$ was the main outcome variable. Using cross tabulations and multivariate analysis, factors associated with psychological distress were identified using the SRQ-25 cut off point of 5. The associations were considered statistically significant if the p-value was $<0.05$.

\section{Results}

\section{Socio-demographics}

One hundred thirty eight (138) of the participants were male and120 were female (male: female ratio of 1.2:1). Majority (60.5\%) of the participants were residents of Mbarara district with the predominant tribe being Banyankore (75\%). About $70 \%$ of the participants were between 18-40 years and only about $10 \%$ were above 60 years. They were aged 18-90 years, with mean age of $37.7(\mathrm{SD}=15.42)$.

Most of the participants had low level of formal education, with primary school level and below accounting for $72 \%$ of the participants. The main religious inclinations were Anglican $56 \%$, Catholic 29.5\%, Moslem 8.5\% and Pentecostal 4.7\%. According their marital status, fifty eighty $(22.5 \%)$ of the participants were single, $151(58.5 \%)$ were married, 31(12\%) were widowed, and 18(7\%) had separated with their spouses. Of the 258 patients enrolled into the study, $152(59 \%)$ were on the medical ward while 106 (41\%) were on the surgical ward. Forty nine percent of the 152 participants on medical ward compared to $60 \%$ on the surgical wards were males. Sixty eight percent of the participants were being hospitalized for the first time, $21 \%$ for the second time and $11 \%$ of them had had two or more previous hospitalizations. Forty three percent of the patients on the medical ward had been hospitalized in the past whereas only $17 \%$ of those on the surgical ward had ever been hospitalized.

\section{Level of Psychological distress and associated factors}

Of the 258 participants of this study, 61\% had psychological distress as defined as having an SRQ25 score of 6 or more. The attending doctors had identified only $6 \%(n=7)$ of them. The diagnoses given to the seven patients were: depression (1), psychotic disorder (2), confusion (2) and suicide attempt (2).

Being separated or widowed, ward of admission being medical ward and having history of previous hospitalization were each associated with psychological distress $(\mathrm{p}<0.05)$. In addition, history of past a psychiatric illness was associated with psychological distress $(p<0.05)$. All the 12 participants with past psychiatric history had psychological distress, with depressive episode being the most frequent in the past psychiatric history. Seventy three percent $(n=111)$ of the patients on medical ward and $43 \%(n=46)$ on the surgical ward scored 6 or more on the SRQ-25. Other factors (e.g. gender, religion, tribe, age, education and district of residence) were not significantly associated with psychological distress in this population ( $\mathrm{p}>0.05)$.

Of the 157 (61\%) with psychological distress, 109 (69\%) participants had diagnosable psychiatric disorders requiring treatment. Diagnosis was made with the use of the DSM IV based MINI International Neuropsychiatric Interview (MINI). Of the 109 patients with psychiatric disorders, 80 (73\%) met criteria for one specific psychiatric diagnosis, 29 $(27 \%)$ met criteria for two or more psychiatric diagnoses with depression $(34 \%)$ being the most common. Details of the psychiatric diagnoses are discussed in a related paper by the same authors. 
Table 1: Independent variables and SRQ Scores

\begin{tabular}{|c|c|c|c|c|c|c|}
\hline Independent variable & $\begin{array}{l}\text { SRQ score } \\
<6 n=101\end{array}$ & $\begin{array}{l}\text { SRQ scoree } \\
>6 \mathrm{n}=157\end{array}$ & Total (N) & Chi-sq & $\mathbf{X}^{2}$ & $\begin{array}{l}\text { P- } \\
\text { value }\end{array}$ \\
\hline \multicolumn{7}{|l|}{ Sex } \\
\hline Male & 41 & 59 & 138 & 0.253 & & n.s \\
\hline Female & 38 & 62 & 120 & & & \\
\hline \multicolumn{7}{|l|}{ Age of patient (yrs) } \\
\hline $18-24$ & 46 & 54 & 50 & 2.676 & & n.s \\
\hline $25-40$ & 39 & 61 & 130 & & & \\
\hline $41-60$ & 40 & 60 & 52 & & & \\
\hline $60+$ & 27 & 73 & 26 & & & \\
\hline \multicolumn{7}{|l|}{ Tribe } \\
\hline Munyankore & 41 & 59 & 194 & 4.860 & & n.s \\
\hline Other & 33 & 67 & 64 & & & \\
\hline \multicolumn{7}{|l|}{ Occupation } \\
\hline Peasant farmer & 33 & 67 & 130 & 8.34 & & n.s \\
\hline Other & 45 & 55 & 128 & & & \\
\hline \multicolumn{7}{|l|}{ Religion } \\
\hline Catholic & 43 & 57 & 76 & 6.015 & & n.s \\
\hline Anglican & 39 & 61 & 145 & & & \\
\hline Other & 32 & 68 & 37 & & & \\
\hline \multicolumn{7}{|l|}{ Level of education } \\
\hline None & 32 & 68 & 41 & & & \\
\hline Primary & 40 & 60 & 144 & 1.302 & & n.s. \\
\hline Secondary/tertiary & 43 & 57 & 73 & & & \\
\hline \multicolumn{7}{|l|}{ Marital status } \\
\hline Single & 36 & 64 & 58 & & & \\
\hline Married/cohabiting & 47 & 53 & 151 & & & \\
\hline Separated/widowed & 18 & 82 & 49 & 13.021 & & $.001^{*}$ \\
\hline \multicolumn{7}{|l|}{ Ward } \\
\hline Medical & 27 & 73 & 152 & 23.000 & & $.001^{*}$ \\
\hline Surgical & 57 & 43 & 106 & & & \\
\hline \multicolumn{7}{|l|}{ Hospitalisations } \\
\hline $1^{\text {st }}$ admission & 45 & 55 & 175 & 10.01 & & $.003^{*}$ \\
\hline Previous admission & 26 & 74 & 83 & & & \\
\hline \multicolumn{7}{|l|}{ Past psychiatri history } \\
\hline Yes & 0 & 12 & 12 & 8.096 & & $.004 *$ \\
\hline No & 101 & 145 & 246 & & & \\
\hline
\end{tabular}

\section{Discussion}

The level of psychological distress among inpatients on the medical and surgical wards at regional referral hospitals cannot be ignored any longer. Of the 109 patients requiring psychiatric/psychological intervention, only 7 of them had been identified. This means that the remaining 102 patients were to remain untreated if the study had not identified them. It is possible that psychological distress is not recognized due to the medico-physical orientation of the health workers forgetting to ask about mood or feelings.
Only $35 \%$ of the female participants were on the surgical ward compared to $51 \%$ on medical ward. This could be because males are more likely to have traumatic experiences e.g. accidents, fractures, burns, etc, due to their day to day chores and activities. The patients who were found to have psychological distress were on many different types of medications. This could have been due to somatic presentation of the psychological distress or the patients appeared to be more ill and had to be put on many drugs or 
the drugs themselves could have caused the psychological distress.

In this study, severe life threatening physical illness, widowhood, re-admission and past history of psychiatric illness were the best predictors of psychological distress. This is in keeping with other studies elsewhere ${ }^{1,15,16,17}$.

The poor recognition of psychiatric distress and psychiatric disorders among the physically ill, is similar to what was found by Nakasujja ${ }^{13}$ at Mulago hospital where only $6 \%$ of the psychiatric disorders among elderly inpatients had been identified by the attending doctors. It is also similar to what was found by Fink and colleagues ${ }^{18}$ in Denmark. They reported that neurologists correctly diagnosed $25 \%$ of patients with depression and missed all the patients with anxiety disorders. The possible reason for poor recognition of psychological distress is the biomedical orientation of the health workers. In addition, some of the features of psychological distress can be constituent features of some physical illnesses/diseases.

\section{Limitations of the study}

This was a regional hospital based study and this could limit generalization of the results to the general community. In addition, the participants in this Study had to be 18 years of age or older excluding younger patients who too were on the general medical and surgical wards. The MINI and the SRQ-25 were not specifically validated for the study population though they have been validated in other African countries, and used widely in Africa including Uganda. The MINI was administered only to patients who scored six or more on the SRQ-25. It is possible that this could have left out those who had psychiatric disorders but with low SRQ-25 scores.

\section{Conclusion}

The high level of psychological distress among the medically ill in Ugandan regional referral hospitals is common and it is not well recognized and therefore not attended to.

\section{Recommendations}

We recommend that assessment for psychological distress should be included in the screening interview of every patient on admission. We also recommend more topics on recognition and management of psychological distress and psychiatric disorders should be included in CME sessions of staff working on the general wards and in all hospitals.

\section{References}

1. Lipowski ZJ. Consultation-Liaison Psychiatry: An overview. American Journal of Psychiatry, 1974;131: 623-630

2. Abiodun OA, Ogunremi, OO. Psychiatric morbidity in medical and surgical wards of a Nigerian general hospital. Journal of Psychosomatic Medicine. 1990; 34 (4):409-14

3. Lloyd GG. Text book of General Hospital Psychiatry. $1^{\text {st }}$ Edition, Longman Singapore publishers ( Pte) Ltd 1991;

4. Moffic HS, Paykel ES. Depression in medical in-patients. British journal of Psychiatry 1995; 126 : 346-353

5. Nakimuli-Mpungu E, Mutamba B, Othengo M, Musisi S. Psychological distress and adherence to highly active anti-retroviral therapy (HAART) in Uganda: A pilot study. African Health Sciences, 2009; 9 (1): S2-S7

6. Ndetei DM, Khasakhala LI, Mutiso V and Mbwayo AW. Suicidality and depression among adult patients admitted in general medical facilities in Kenya. Annals of General Psychiatry, 2010; 9:7

7. Moussavi S, Chatterji S, Verdes E, Tandon A, Patel V, Ustun B. Depression, chronic diseases, and decrements in health: results from the World Health Surveys. 2007; (8); 370 (9590):851-8.

8. Patel V. Integrating mental health care with chronic diseases in low-resource settings. International Journal of Public Health 2009; 54; S1S3

9. Katon W, Lin E, Korff VM et al. Somatization a spectrum of severity. American Journal of Psychiatry 1991; 148:1.

10. Kirmayer LJ, Robbins JM, Dworkin M, Yaffe MJ.Somatization and the recognition of Depression and anxiety in primary care. American Journal of Psychiatry 1993; 150:734-741

11. Musisi S, Kinyanda E. The psychological and social problems of HIV Seropositive Adolescents \& parents /guardians at Mildmay centre, Kampala-Uganda, Proceeds of the World Psychiatric Association Eastern Africa Regional Psychiatric conference, Nairobi, April 2003.

12. Husain N, Humail SM, Chaudhry IB, Rahman R, Robinson $\mathrm{H}$ and Creed F. Annals of General Psychiatry 2010; 9:9

13. Nakasujja N. Psychiatric disorders among elderly in-patients on non-psychiatric Wards of Mulago 
hospital. M.Med Thesis, Makerere University Kampala Uganda, 2002; page 32-40

14. Katorogo JB. Prevalence of Depressive symptoms among medically ill in-patients; Thesis Diploma in Clinical Mental Health, Butabika Hospital, Ministry of Health, Uganda. 2001; page 22-37.

15. Clarke DM, Minas IH, Stuart GW. The prevalence of psychiatric morbidity in general hospital (Prince Henry's hospital, Melbourne) inpatients. British Journal of Psychiatry. 1989; 154:504-9.

16. Botega NJ, Pereira, WA, Bio MR, Junior C, Zomignani, MA. Psychiatric morbidity among medical in-patients: a standardized assessment (GHQ-12 and CIS-R) using 'lay' interviewers in a Brazilian hospital. Acta Psychiatrica Scandinavia, 1997; 96 (1):31-35

17. Deshpande SN, Sundaram KR, Wig NN. Psychiatric disorders among medical in-patients in an Indian hospital (Safdarjang Hospital). Encephale. 2001; 27(3):238-44.

18. Fink P, Hansen MS, Sondergaard L, Frydenberg. Mental illness in new neurological patients. Journal of Neurology Neurosurgery and psychiatry. 2003; 74: 817-819 